Thorax (1973), 28, 701.

\title{
Pathology of chronic mountain sickness
}

\author{
JAVIER ARIAS-STELLA, HEVER KRÜGER, and \\ SIXTO RECAVARREN
}

Institute for High Altitude Investigations, Universidad Peruana 'Cayetano Heredia', Lima, Peru

\begin{abstract}
Arias-Stella, J., Krüger, H., and Recavarren, S. (1973). Thorax, 28, 701-708. Pathology of chronic mountain sickness. Pathological data on chronic mountain sickness are scarce due to the fact that the disease is ameliorated or cured by descent to a low altitude. In this report we describe a case of chronic mountain sickness occurring in a woman of 48 years at Cerro de Pasco (4,300 $\mathrm{m}$ above sea level). The necropsy findings are compared with the limited pathological observations reported by others. It is apparent from our findings that in fatal cases the main changes are located within the pulmonary circulation. So far histological studies have been reported only in cases of the secondary form of chronic mountain sickness. The basic pathology of the primary form (Monge's disease) remains to be defined.
\end{abstract}

The terms chronic mountain sickness, chronic soroche, high altitude disease, or Monge's disease have been used to define the condition of loss of natural or acquired acclimatization occurring in people living at high altitude (Monge and Monge, 1966). These terms have been applied to persons native to high altitude and to emigrants from sea level. The disease is characterized by an accentuation of changes associated with hypoxaemia, such as increased oxygen arterial unsaturation, polycythaemia, and pulmonary arterial hypertension. Clinical features include cyanosis, headache, insomnia, and paraesthesiae. The signs and symptoms are progressive and eventually lead to chronic cor pulmonale and cardiac insufficiency. Hypoventilation due to a diminished response to the stimulus of carbon dioxide and/or hypoxaemia has been suggested as the basic pathogenic mechanism (Hurtado, 1966; Severinghaus, Bainton, and Carcelen, 1966). While the disease is relatively frequent above $3,500 \mathrm{~m}$ and is easily recognized on clinical grounds, a clear definition of its pathological nature is still lacking because the disease is ameliorated or cured by descent to sea level.

TYPES OF CHRONIC MOUNTAIN SICKNESS It is evident from published reports (Arias-Stella, 1971) that the term 'chronic mountain sickness' is used to describe any disease which presents with some of the signs and symptoms listed above

Requests for reprints: Professor J. Arias-Stella, Institute for High Altitude Investigations, Universidad Peruana, 'Cayetano Heredia', Lima, Peru in a person living at high altitude. We propose to distinguish three clinicopathological types of chronic mountain sickness:

TYPE 1 This occurs in subjects who, for professional or other reasons, move from sea level to live at high altitude and never adapt to this change. Detailed reports on these cases are lacking. Monge (1943) specifically mentioned them without giving details of individual cases. More recently, isolated examples have been reported (Figallo, 1971 ; Sobrevilla, 1971). However, a similar condition known as 'brisket disease' has been described in detail by Glover and Newson (1915 and 1918) and by Hecht et al. (1962) in cattle grazing at high altitude in the region of Salt Lake City. The basic pathogenic mechanism in this type of chronic mountain sickness is a failure of homeostatic adjustment to the atmosphere at high altitude. Since Monge (1943) used the terms acute, subacute, and chronic soroche for the illness which may occur during adaptation to high altitude, we propose that type I chronic mountain sickness be designated 'chronic soroche'.

TYPE II This form of the disease is seen among people from sea level who have already adapted and have been living in good health at high altitudes, or among natives of the Andes in whom organic disease exaggerates the hypoxaemic state. This may occur in patients with obesity, kyphoscoliosis, and neuromuscular disorders affecting the thoracic cage, or any other condition that influences pulmonary function such as emphysema, tuberculosis, and pneumoconiosis. Monge 
recognized such cases as secondary chronic mountain sickness (Monge and Monge, 1966), and so we propose that this type be designated 'Monge's syndrome'.

TYPE III This type is seen in people who are native to or in those who have adapted to life at high altitude and who later develop the features of chronic mountain sickness although no organic disease is found to explain their increased hypoxaemia. These cases have been well documented (Monge, 1928; Hurtado, 1942; Peñaloza and Sime, 1971) and have been attributed to a decreased sensitivity of the respiratory centre to carbon dioxide and/or of the chemoreceptors to hypoxaemia. This leads to hypoventilation and thus to increasing systemic arterial unsaturation. We believe that the designation 'Monge's disease' should be reserved for this type of chronic mountain sickness.

A 'primary' form of hypoventilation syndrome has been described at sea level (Rodman and Close, 1959; Richter, West, and Fishman, 1957). In this syndrome there is no obesity nor any underlying pulmonary, cardiovascular, or neuromuscular cause for the hypoventilation. There is a diminished ventilatory response to hypoxaemia and hypercapnia so that polycythaemia and cyanosis develop. It seems likely that the primary hypoventilation syndrome is the condition corresponding to Monge's disease at sea level. At sea level the primary hypoventilation syndrome is rare whereas in the Andes Monge's disease is relatively common. The reason for this may be that persistent systemic arterial unsaturation at high altitude can lead to permanent desensitization of the chemosensitive respiratory mechanism. In this respect it is interesting that Sorensen and Severinghaus (1968) found that chronic hypoxia during the first two years of life desensitizes irreversibly the reflex response to acute hypoxia mediated by peripheral chemoreceptors. On the other hand, we have found that the carotid bodies are larger and heavier at high altitude (AriasStella, 1969).

\section{PATHOLOGICAL STUDIES IN FATAL CHRONIC MOUNTAIN SICKNESS}

We have been able to find only two references to histopathological observations in fatal cases of chronic mountain sickness. In 1961 FernanZegarra and Lazo-Taboada reported the case of a man of 35 years, a native of Caylloma $(4,320 \mathrm{~m})$, who had been admitted to hospital in Arequipa several times since 1954. He complained of progressive dyspnoea, oedema, and cyanosis, which were considered characteristic of Monge's disease. An electrocardiogram showed right ventricular preponderance. His last admission to hospital was on 11 August, 1958. He died 45 days after admission with the clinical picture of cardiac failure. His haemoglobin level was $25.5 \mathrm{~g} / 100 \mathrm{ml}$. At necropsy he was found to have scoliosis, hypertrophy of the right and left ventricles, dilatation and atheroma of the pulmonary trunk, and marked congestion of the liver and brain. Note is made of 'thickening of the pulmonary arterioles due to fibrosis and moderate muscular hypertrophy'. The final diagnosis reached was cardiac insufficiency due to chronic mountain sickness.

Reategui-López (1969) reported 30 cases of chronic mountain sickness studied at Cuzco $(3,339 \mathrm{~m})$ over a period of nine years. It is of interest to note that half of these patients were frankly obese. Five cases proved to be fatal, but a necropsy was carried out in only two. Such brief comments on the findings as were given are summarized in the Table.

We have had the opportunity to study a third case of chronic mountain sickness in which a complete necropsy was carried out. A woman of

T A B L E

MAIN PATHOLOGICAL FEATURES IN REPORTED CASES OF FATAL CHRONIC MOUNTAIN SICKNESS

\begin{tabular}{|c|c|c|c|c|}
\hline Author & Heart & Lungs & Observation & Cause of Death \\
\hline $\begin{array}{l}\text { Fernan-Zegarra and } \\
\text { Lazo-Taboada (1961) }\end{array}$ & \multirow{4}{*}{$\begin{array}{l}\text { R. and L. ventricular } \\
\text { hypertrophy } \\
\text { Heart } 750 \mathrm{~g} \\
\text { (1) R. ventricular } \\
\text { hypertrophy } \\
\text { (2) R. ventricular } \\
\text { hypertrophy } \\
\text { R. ventricular hypertrophy } \\
\text { Heart } 370 \mathrm{~g}\end{array}$} & \multirow{4}{*}{$\begin{array}{l}\text { Peripheral pulmonary } \\
\text { arterial intimal and medial } \\
\text { thickening } \\
\text { Peripheral pulmonary } \\
\text { arterial thickening } \\
\text { Peripheral pulmonary } \\
\text { arterial thickenings } \\
\text { emphysema } \\
\text { Peripheral pulmonary } \\
\text { arterial intimal and medial } \\
\text { thickening; fresh and } \\
\text { organized pulmonary } \\
\text { arterial thrombi; chronic } \\
\text { bronchiolitis }\end{array}$} & Right & $\begin{array}{l}\text { Severe cardiac } \\
\text { insufficiency }\end{array}$ \\
\hline Reategui-López (1969) & & & Obesity & Cardiac insufficiency \\
\hline & & & Obesity & Cardiac insufficiency \\
\hline $\begin{array}{l}\text { Arias-Stella, Krüger, and } \\
\text { Recavarren (1971) }\end{array}$ & & & $\begin{array}{l}\text { Dorsal } \\
\text { kyphoscolio- } \\
\text { sis }\end{array}$ & $\begin{array}{l}\text { Cardiac insufficiency due } \\
\text { to chronic cor } \\
\text { pulmonale }\end{array}$ \\
\hline
\end{tabular}


48 years, who was born and had lived all her life in Cerro de Pasco (4,375 m), complained that for three years before admission to hospital she had been breathless, first on effort and finally at rest. She was unable to sleep in an upright position. During the last weeks before admission she developed pitting oedema of the lower limbs. She had a productive cough with haemoptysis. Clinical examination revealed pitting oedema of the ankles, cyanosis of the hands and face, and crepitation at the lung bases. Her systemic blood pressure was $110 / 70 \mathrm{mmHg}$.

There were $7 \cdot 5$ million red cells $/ \mathrm{mm}^{3}, 6,600$ white cells $/ \mathrm{mm}^{3}$, and the differential count was as follows: neutrophils $87 \%$, eosinophils $1 \%$, lymphocytes $12 \%$. Haemoglobin $21.6 \mathrm{~g} \%$. ESR $2 \mathrm{~mm}$ per hour (Wintrobe). The urine contained red cells and traces of albumin.

The following was the opinion of Monge (1967), who first described chronic mountain sickness, on the clinical history of this case: 'Evidently this is a case of chronic mountain sickness, primary because of loss of acclimatization or secondary due to other causes. I have seen similar cases but have not dared to report them because of insufficient clinical data. I remember one patient who developed extreme anasarca and eliminated her oedema simply by coming down to the coast.'

The patient died 13 days after admission. At necropsy she weighed $47 \mathrm{~kg}$ and was $1.30 \mathrm{~m}$ in height. She had generalized oedema and a deep bluish tint to the mucosae and limbs. There was

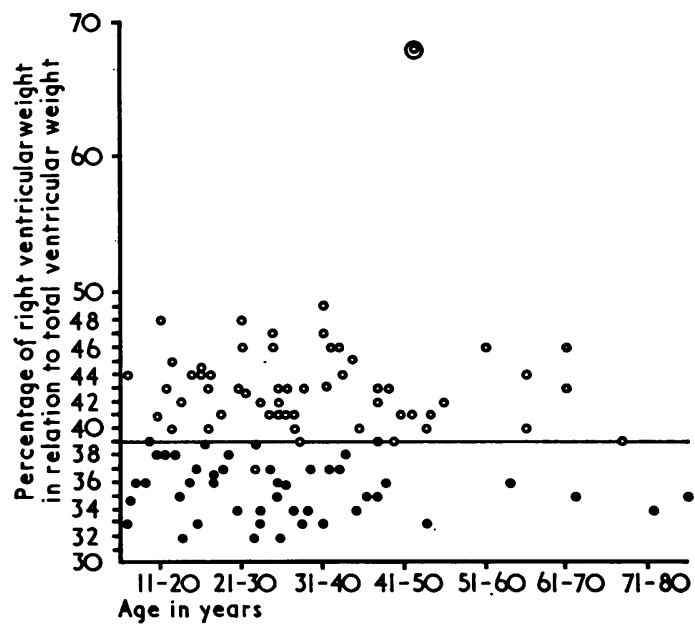

FIG. 1. Right ventricular weight as a percentage of total ventricular weight in individuals at sea level and at high altitude, in comparison with the case of chronic mountain sickness (high altitude: Cerro de Pasco 4,375 m): $\bigcirc$ high altitude; sea level; () chronic mountain sickness. pronounced dorsal kyphoscoliosis which deformed the thoracic cage so that the anteroposterior diameter was greater than the transverse. The heart weighed $320 \mathrm{~g}$. There was hypertrophy and dilatation of the right ventricle and dilatation of the right atrium. The Hermann and Wilson index was below $1 \cdot 0$, confirming a severe degree of right ventricular hypertrophy. Figure 1 expresses the right ventricular weight as a percentage of total ventricular weight, in comparison with the values found in normal cases at sea level and at high altitude (Recavarren and Arias-Stella, 1964). There was severe atheroma in the pulmonary trunk and its main branches. The lungs were congested, the right weighing $360 \mathrm{~g}$ and the left $270 \mathrm{~g}$. There were bilateral pleural effusions of a transparent yellow fluid, while the peritoneal cavity held 6 litres of a similar fluid. The liver, kidneys, and brain were congested. The lungs were fixed by perfusion of the bronchial tree with $10 \%$ formalin followed by immersion of the lungs in this fixative for seven days. The pulmonary arteries were then studied morphometrically (AriasStella and Saldaña, 1963).

Histological study of the lungs showed congested but otherwise unaffected alveoli (Fig. 2) and an intense muscularization of the peripheral portions of the pulmonary arterial tree (Fig. 3). There was some intimal fibrosis in small and medium sized pulmonary arterial branches (Fig. 4). Fresh and partially organized thrombi were found in the large, medium, and small pulmonary arteries (Figs. 5 and 6).

In Fig. 7 the distribution of the areas of peripheral arterial muscle by age and altitude is shown in comparison with the results in this case.

There was chronic bronchitis mainly affecting airways lined by tall columnar epithelium but not those lined by low cuboidal epithelium or respiratory bronchioles; it was characterized by a cellular infiltration of the bronchial wall. In one section of the right middle lobe there was slight centrilobular emphysema with some fibrous thickening of the alveolar walls. In the right lower lobe there was oedema and haemorrhage into the alveoli. There was pronounced congestion of the viscera. A nodular goitre was found, and in the adrenals there were nodular foci of glomerular cells. A routine histological examination of the brain showed no obvious pathological features. It was considered that this was a case of cardiac insufficiency secondary to chronic cor pulmonale. The degree of right ventricular hypertrophy and muscularization of the peripheral pulmonary arterial branches considerably exceeded the values normally found at high altitudes. 


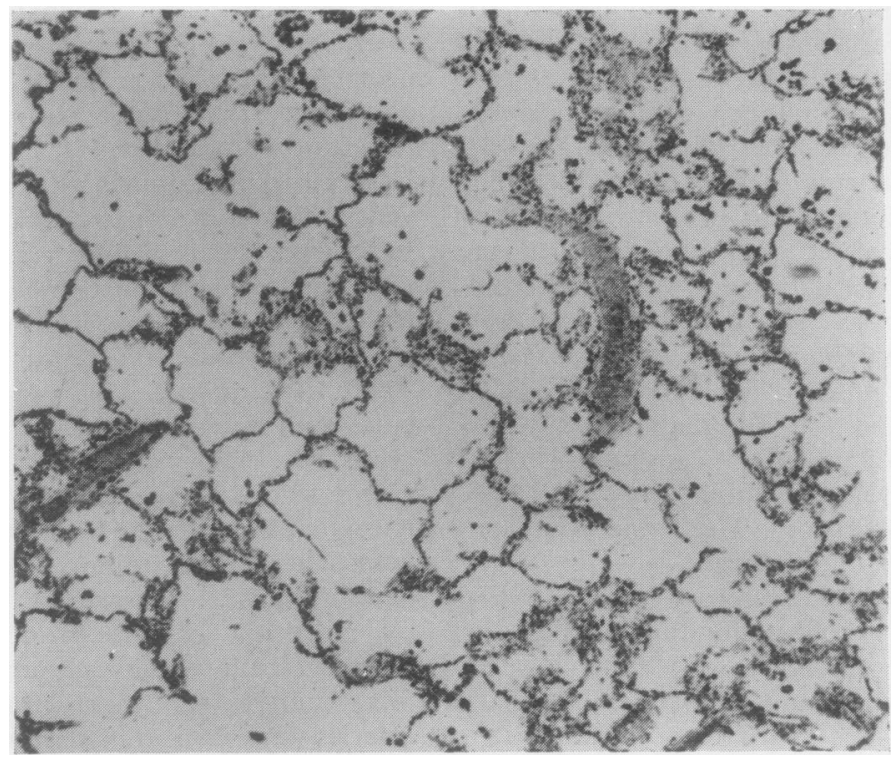

FIG. 2. Panoramic view of the lung parenchyma. Focal septal congestion can be seen. The alveolar walls are normally thin. $(H$ and $E \times 80)$.

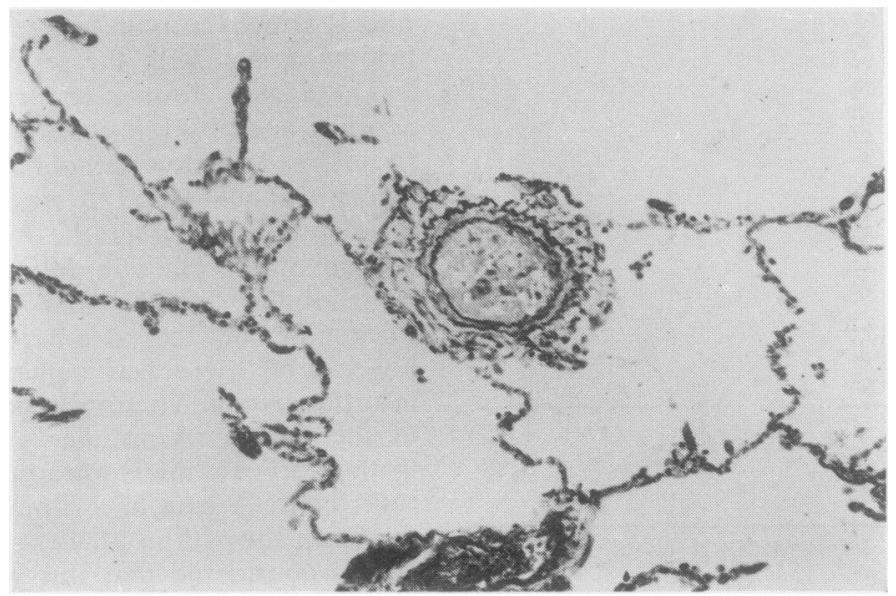

FIG. 3. Pulmonary arterial branch at the level of the alveolar ducts. The vessel shows well-defined double elastic laminae. Structurally, this is an artery and not an arteriole as normally seen in this position in the adult. (van Gieson Weigert $\times 250$ ) 


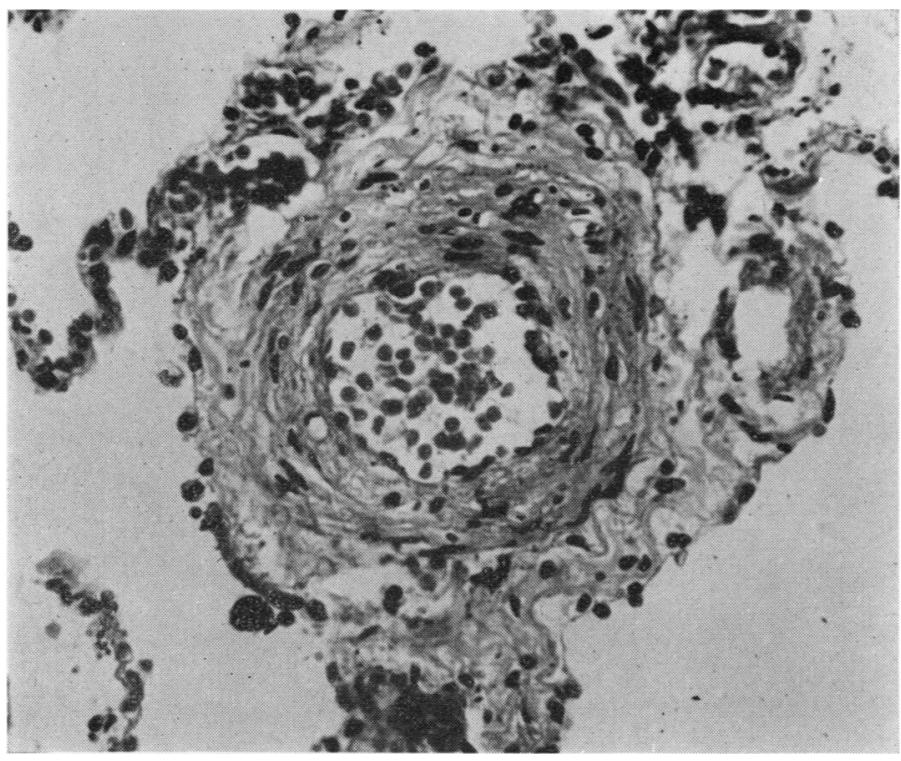

FIG. 4. Fibrotic intimal thickening in small pulmonary arterial branch. ( $H$ and $E \times 500)$

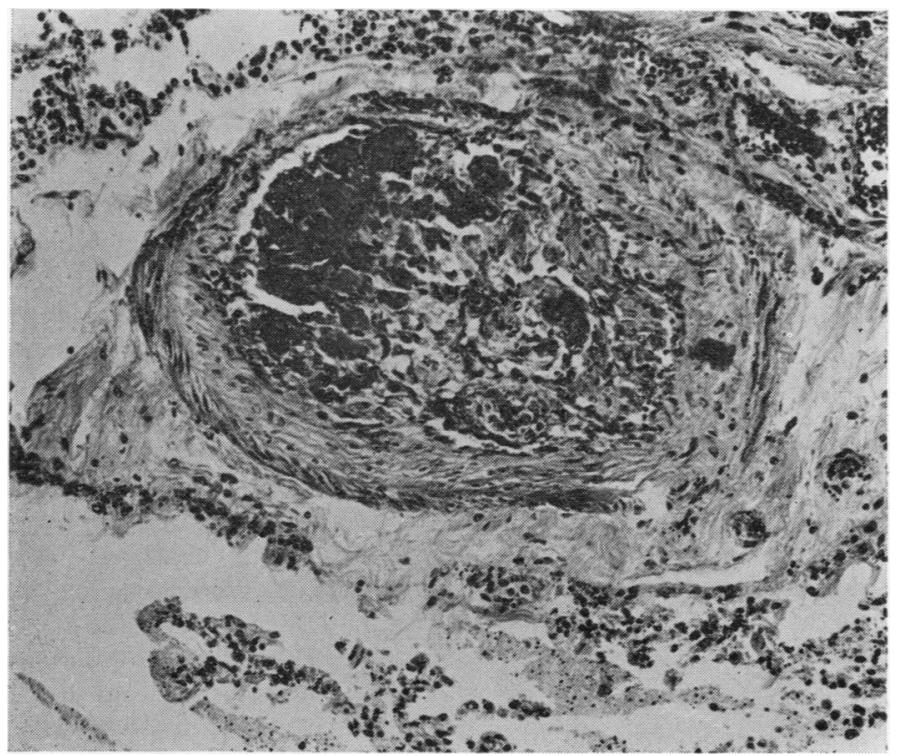

FIG. 5. Pulmonary arterial muscular branch, of medium size, showing almost complete occlusion by partially organized thrombus. ( $H$ and $E$ $\times 300$ ) 


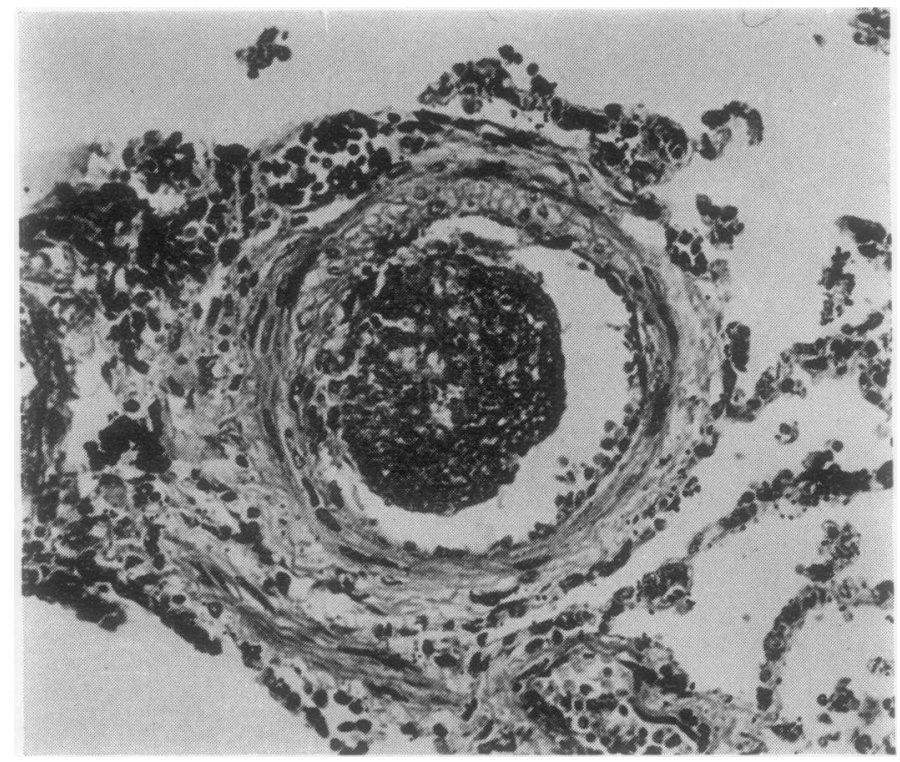

FIG. 6. Small pulmonary arterial branch with fresh thrombus. ( $H$ and $E$ $\times 350)$

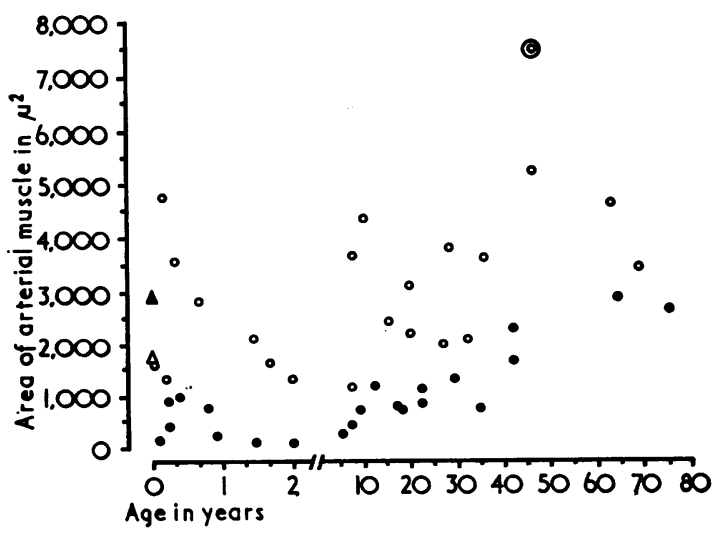

FIG. 7. Area of pulmonary arterial muscle at distal level, by age and altitude, in comparison with the case of chronic mountain sickness. $\bigcirc$ high altitude; 1 sea level; (O) chronic mountain sickness; $\triangle$ high altitude new born (average of 7 cases); $\Delta$ sea level new born (average of 8 cases) (high altitude: Cerro de Pasco 4,375 m).

\section{DISCUSSION}

In the Table the main pathological features in reported cases of fatal chronic high altitude dis?. ease are summarized. It is clear that all the fatab cases reported so far are what we term Monge's? syndrome or type II chronic mountain sickness? In two of the cases some form of scoliosis wass present. The first problem to solve is whether the pulmonary histopathological findings correspond to those reported in kyphoscoliosis.

Studies of the lungs in kyphoscoliosis have shown a variety of changes: emphysema, pneumonia bronchitis, atelectasis or bronchiolectasis (Chap man, Dill, and Graybiel, 1939 ; Fisher and Doleo hide, 1954 ; Reid, 1966). The changes are unevenly distributed throughout the lung parenchyma and? there is no consistent nor characteristic lesion.0 The frequency of right ventricular hypertrophye has been variously attributed to collapse, conges@ tion, the small size of the pulmonary vascula $\vec{E}$ bed, arterial medial hypertrophy, hypoxaemia 
atrophy, and hypoplasia (Davies and Reid, 1971). Those who have studied the pulmonary arterial vessels in kyphoscoliosis have reported no abnormality at all (Fisher and Dolehide, 1954), 'hypoplasia of the pulmonary arterial bed' (Reid, 1966), or minor to moderate degrees of muscularization of the pulmonary arteries (Bergofsky, Turino, and Fishman, 1959; Naeye, 1961). Whether the increase in pulmonary vascular resistance leading to cor pulmonale is due to mechanical circulatory disturbance secondary to the chest deformity or to hypoxaemia, the fact is that those cases of kyphoscoliosis with signs of right ventricular overload usually show some degree of muscularization in the pulmonary arterial branches (Davies and Reid, 1971). Hasleton, Heath, and Brewer (1968) have described the morphological pattern of pulmonary arterial changes associated with chronic hypoxia, including kyphoscoliosis, as follows: '(1) Muscularization of the pulmonary arterioles, which normally have a wall consisting of a single elastic lamina; (2) absence of hypertrophy of the muscular pulmonary arteries; and (3) the development of intimal longitudinal muscle in muscular pulmonary arteries and in arterioles.'

The case of chronic mountain sickness that we have studied showed no major structural distortion of the lungs, but there was a degree of muscularization of the peripheral pulmonary arterial branches which exceeded that expected for the altitude. There was also intimal thickening in small and medium sized pulmonary arterial branches with fresh and partially organized thrombi, and these changes are not usually found in kyphoscoliosis at sea level. We therefore conclude that, in the present case, the respiratory effects of the kyphoscoliosis were aggravated by the hypoxic environment and that this produced the clinical picture of chronic mountain sickness with severer vascular changes than those seen at sea level. Chronic bronchiolitis may also have contributed to the hypoxaemic state. Obesity is another condition known to lead to chronic cor pulmonale as in the series reported by ReateguiLópez (1969).

The fatal cases of chronic mountain sickness reported by Fernan-Zegarra and Lazo-Taboada (1961), by Reategui-López (1969), and by the present authors indicate that the clinical picture of chronic mountain sickness may develop when conditions known to affect the physiology of respiration occur at high altitudes.

It is not surprising, therefore, that Heath (1971) has questioned the existence of Monge's disease as a primary pathological entity. He claims that it is necessary to demonstrate the pathology of Monge's disease before it can be accepted as a distinct condition. He suggests that some cases may represent unrecognized centrilobular emphysema in persons living at high altitude. Hurtado (1971) has argued against this viewpoint on the grounds that a similar argument could be applied to deny the existence of certain mental diseases.

Owing to the shape of the haemoglobin oxygen dissociation curve, oxygen exchange in the lungs takes place, at high altitudes, on the descending part of the curve so that even a small decrement of $\mathrm{Po}_{2}$ produces a significant reduction in arterial oxygen saturation. Thus a moderate impairment of ventilation at high altitude could reduce the already low arterial oxygen saturation to intolerable levels. On this basis it is easy to understand why even a minimal respiratory disorder can induce severe hypoxaemia at high altitude. A further complication is that sustained hypoxaemia can temporarily or permanently diminish the sensitivity of the chemoreceptors and/or the respiratory centre (Severinghaus et al., 1966; Sorensen and Severinghaus, 1968) and thus a vicious circle is established, leading to progressive hypoventilation.

The fact remains that up to the present there are no detailed reports on the pathology of primary chronic mountain sickness. Only when such data become available will the controversy about the existence of a distinct pathological entity, Monge's disease, be resolved.

\section{REFERENCES}

Arias-Stella, J. (1969). The human carotid body at high altitudes. American Journal of Pathology, 55, 82a (abstract).

(1971). Chronic mountain sickness: pathology and definition. In high altitude physiology: cardiac and respiratory aspects: $A$ Ciba Foundation Symposium, edited by Ruth Porter and Julie Knight, p. 31. Churchill Livingstone, Edinburgh and London.

—and Saldaña, M. (1963). Terminal portion of the pulmonary arterial tree in people native to high altitudes. Circulation, 28, 915.

Bergofsky, E. H., Turino, G. M., and Fishman, A. P. (1959). Cardiorespiratory failure in kyphoscoliosis. Medicine, 38, 263.

Chapman, E. M., Dill, D. B., and Graybiel, A. (1939). Decrease in functional capacity of the lungs and heart resulting from deformities of the chest; pulmonocardiac failure. Medicine, 18, 167.

Davies, G. and Reid, L. (1971). Effect of scoliosis on growth of alveoli and pulmonary arteries and on right ventricle. Archives of Diseases in Childhood, 46, 623. 
Fernan-Zegarra, L., and Lazo-Toboada, F. (1961). Mal de montaña crónico. Consideraciones anatomopatológicas y referencias clínicas de un caso. Revista Peruana de Patologia, 6, 49.

Figallo, M. A. (1971). Personal communication.

Fisher, J. W. and Dolehide, R. A. (1954): Fatal cardiac failure in persons with thoracic deformities. Archives of Internal Medicine, 93, 687.

Glover, H. and Newson, I. E. (1915). Brisket disease (dropsy of high altitudes). The Agricultural Experiment Station of the Colorado Agricultural College Bulletin, 204.

- _- (1918). Further studies on brisket disease. Journal of Agricultural Research, 15, 409.

Hasleton, P. S., Heath, D., and Brewer, D. B. (1968). Hypertensive pulmonary vascular disease in states of chronic hypoxia. Journal of Pathology and Bacteriology, 95, 431 .

Heath, D. (1971). In: Discussion-Cor Pulmonale in chronic mountain sickness: present concept of Monge's disease in High Altitude Physiology: Cardiac and Respiratory Aspects. A Ciba Foundation Symposium, edited by Ruth Porter and Julie Knight, p. 52. Churchill Livingstone, Edinburgh and London.

Hecht, H. H., Kuida, H., Lange, R. L., Thorne, J. L., and Brown, A. M. (1962). Brisket disease. II. Clinical features and hemodynamic observations in altitudedependent right heart failure of cattle. American Journal of Medicine, 32, 171.

Hurtado, A. (1942). Chronic mountain sickness. Journal of the American Medical Association, 120, 1278.

, (1966). Aclimatación a la altura. Conferencias Eduardo Braun Menéndez. Compañía Impresora Argentina S.A., Buenos Aires.

(1971). In: Discussion-Cor Pulmonale in chronic mountain sickness: present concept of Monge's disease in High Altitude Physiology: Cardiac and Respiratory Aspects. A Ciba Foundation Symposium, edited by Ruth Porter and Julie Knight, p. 52. Churchill Livingstone, Edinburgh and London.
Monge, M., C.(1928). La enfermedad de los Andes, sindromes eritrémicos. Anales de la Facultad de Medicina de Lima, $11,314$.

- (1943). Chronic mountain sickness. Physiological Reviews, 23, 166.

(1967). Personal communication.

and Monge, C., C. (1966). In: High Altitude Diseases. Mechanism and Management. Thomas, Springfield, Illinois.

Naeye, R. L. (1961). Kyphoscoliosis and cor pulmonale: a study of the pulmonary vascular bed. American Journal of Pathology, 38, 561.

Peñaloza, D. and Sime, F. (1971). Chronic cor pulmonale due to loss of altitude acclimatization (chronic mountain sickness). American Journal of Medicine, 50, 728.

Reategui-López, L .(1969). Soroche crónico. Observaciones realizadas en el Cuzco en 30 casos. Revista Peruana de Cardiología, 15, 45.

Recavarren, S. and Arias-Stella, J. (1964). Right ventricular hypertrophy in people born and living at high altitudes. British Heart Journal, 26, 806.

Reid, L. (1966). Autopsy studies of the lungs in kyphoscoliosis. In: Proceedings of a Symposium on Scoliosis, edited by P. A. Zorab, pp. 71-78. National Fund for Research into Poliomylitis and other Crippling Disease, London.

Richter, T. West, J. R., and Fishman, A. P. (1957). The syndrome of alveolar hypoventilation and diminished sensitivity of the respiratory center. New England Journal of Medicine, 256, 1165.

Rodman T. and Close, H. P. (1959). The primary hypoventilation syndrome. American Journal of Medicine, 26, 808.

Severinghaus, J. W., Bainton, C. R., and Carcelen, A. (1966). Respiratory insensitivity to hypoxia in chronically hypoxic man. Respiration Physiology, 1, 308 .

Sobrevilla, L. (1971). Personal communication.

Sorensen, S. C. and Severinghaus, J. W. (1968). Irreversible respiratory insensitivity to acute hypoxia in man born at high altitude. Journal of Applied Physiology, 25, 217. 